\title{
Activation of the PKB/Akt pathway in histological benign prostatic tissue adjacent to the primary malignant lesions
}

\author{
AXEL S. MERSEBURGER ${ }^{1}$, JÖRG HENNENLOTTER ${ }^{1}$, PERIKLES SIMON ${ }^{2}$, \\ CAROLIN C. MÜLLER ${ }^{1}$, URSULA KÜHS ${ }^{1}$, RUTH KNÜCHEL-CLARKE ${ }^{3}$, \\ JUDD W. MOUL ${ }^{4}$, ARNULF STENZL ${ }^{1}$ and MARKUS A. KUCZYK ${ }^{1}$ \\ ${ }^{1}$ Department of Urology, Eberhard Karls University Tuebingen, Hoppe-Seyler-Str. 3; \\ ${ }^{2}$ Department of Medicine, Section of Sportmedicine, Eberhard Karls University Tuebingen, \\ Silcherstr 5, D-72076, Tuebingen; ${ }^{3}$ Department of Pathology, University of Aachen, Aachen, \\ Germany; ${ }^{4}$ Division of Urologic Surgery, Duke University Medical Center, Durham, NC, USA
}

Received November 24, 2005; Accepted January 9, 2006

\begin{abstract}
In order to evaluate the molecular heterogeneity of prostate cancer, this study examined the expression of Aktpathway related parameters within the cancerous prostate gland. PTEN, p-Akt and p27kip1 are known to be altered in prostate cancer. Tissue samples from malignant, tumor adjacent benign and benign areas of 25 whole mounted prostate cancer specimens were processed to 583 tissue microarray cores. Immunohistochemically determined biomarker expression was correlated to the different localizations. p-Akt and p27kip1 showed increased staining in malignant tissue compared to the respective benign tissue $(\mathrm{p}<0.01$ and $\mathrm{p}<0.05)$. The adjacent but histologically benign tissue had increased levels $(\mathrm{p}<0.05$ and $\mathrm{p}<0.01$ ), whereas no significant difference was found between the adjacent and malignant regions. A highly significant correlation of $\mathrm{p}$-Akt and $\mathrm{p} 27^{\mathrm{kip} 1}$ in benign tissue $(\mathrm{p}<0.001)$ was lost in the adjacent areas and in the malignant tissue ( $\mathrm{p}=0.054$ and $\mathrm{p}=0.12$ ). In tendency, PTEN expression was decreased in the malignant regions and revealed the highest staining in the adjacent zone. According to the results obtained, the expression of p-Akt and p27 $7^{\mathrm{kip} 1}$ was increased in both the adjacent microscopically benign tissue as well as the primary tumors when compared with the histologically benign tissue specimens that served as biological control. The increased expression of PTEN indicates its regulatory function in the initial steps of a deteriorated cell cycle control as well as uncontrolled cellular proliferation, for example,
\end{abstract}

Correspondence to: Professor Markus A. Kuczyk, Department of Urology, Eberhard Karls University Tuebingen, Hoppe-Seyler-Str. 3, D-72076 Tuebingen, Germany

E-mail: markus.kuczyk@med.uni-tuebingen.de

Key words: prostate cancer, localized diversity, PTEN, p-Akt, p27 kip1, tissue microarray which seem to be present in the normal prostatic tissue surrounding the primary malignant lesion. The addition of molecular markers to a 'classical' histopathological approach might contribute to an enhanced sensitivity of analytical approaches aimed at the detection of malignant or premalignant lesions within prostatic biopsies.

\section{Introduction}

The histopathological heterogeneity of prostate cancer is a well-known fact (1-3), whereas less is known about molecular heterogeneity within the cancerous prostate gland. Certain molecular parameters are known to be altered in prostate cancer tissue. This study examined Akt-pathway related parameters PTEN, p-Akt and p27kip1 with regards to their expression in benign, adjacent benign and prostate cancer tissue. PTEN, p-Akt, p27 ${ }^{\text {kip } 1}$ are important check-points of cell cycle control, tumor growth and differentiation in prostate cancer (4).

The PTEN tumor suppressor gene is one of the most frequently deleted genes in various human cancers, including prostate cancer $(5,6)$. The main function of PTEN relies on its phosphatase activity and subsequent antagonism of the PI3K/Akt pathway $(7,8)$. Loss of PTEN function results in accumulation of $\mathrm{PIP}_{3}$ and activation of its downstream effectors, including Akt (9-11).

As a serine/threonine protein kinase, Akt functions by phosphorylating key intermediate signalling molecules, leading to an increase in cell metabolism, cell growth and cell survival (12). Further, Akt activation seems to be important for the progression of prostate cancer to an androgen-independent state (13).

The $\mathrm{p} 27^{\mathrm{kip} 1}$ protein regulates cell-cycle progression from the G1-phase to S-phase by its inhibitory interaction with the cyclinE/cdk2 complex. Loss of p2 $7^{\mathrm{kip} 1}$ expression has been shown to be a negative prognostic marker in various carcinomas as well as in prostatic carcinoma (14). Low levels of p27kip1 may be as much a result of CDKN1B alterations as of PTEN loss, whose function is mediated by the Akt-signalling path- 


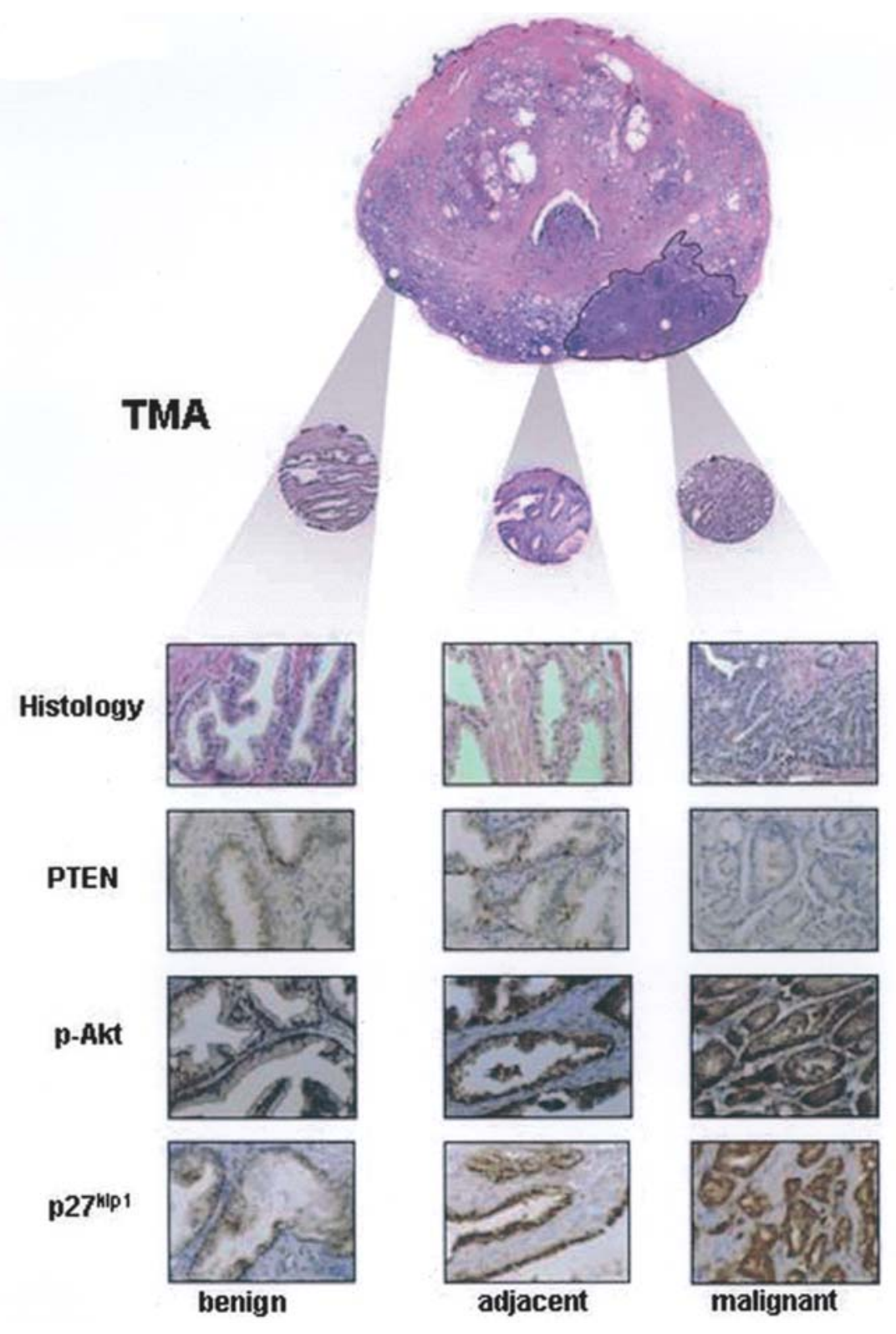

Figure 1. Representative staining of the 3 parameters in benign, adjacent and malignant tissue.

way (15). The objective of the present investigation was to investigate the local diversity of aforementioned molecular markers within the prostate gland compared to histology.

\section{Materials and methods}

Patients. The study included 25 patients subjected to radical prostatectomy who had been diagnosed with prostate cancer between April and July 2003 at the Tuebingen University Hospital. The patients' ages at surgery ranged from 46 to 71 (median, 60.5) years.

Formalin-fixed radical prostatectomy specimens were cut by a cold meat slicer into 3-mm serial whole mount horizontal sections, perpendicular to the dorsal face. Four to six sections from each prostate were processed for TMA retrieval.

Procedures. Representative areas of paraffin embedded tissue lamellas were selected by means of primary evaluation of the
HE-stained whole mount slides. Tissue specimens obtained from the primary tumor area, benign regions and benign regions 2-3 $\mathrm{mm}$ adjacent to the tumor area were constructed for tissue microarrays as previously described (16-18). TMAs contained 583 samples, including 150 benign, 300 adjacent benign and 129 tumor tissues; four tissue cores were excluded from analysis due to insufficient adhesion on the glass slides.

Expression of PTEN, p-Akt and p27 ${ }^{\mathrm{kip} 1}$ was determined by immunohistochemistry. TMA sections were deparaffinized, rehydrated and immersed in 3\% hydrogen peroxide solution to block endogenous peroxidase activity. Antigen retrieval was accomplished by microwave heating specimens in a $0.01 \%$ citrate buffer for $15 \mathrm{~min}$. Biomarker expression was immunohistochemically detected by commercially available antibodies (PTEN and p27kip1 monoclonal mouse, p-Akt polyclonal, Cell Signaling Technology, Inc., Beverly, MA, USA). The optimal dilutions were: PTEN and p27kip1, 1:200; and 

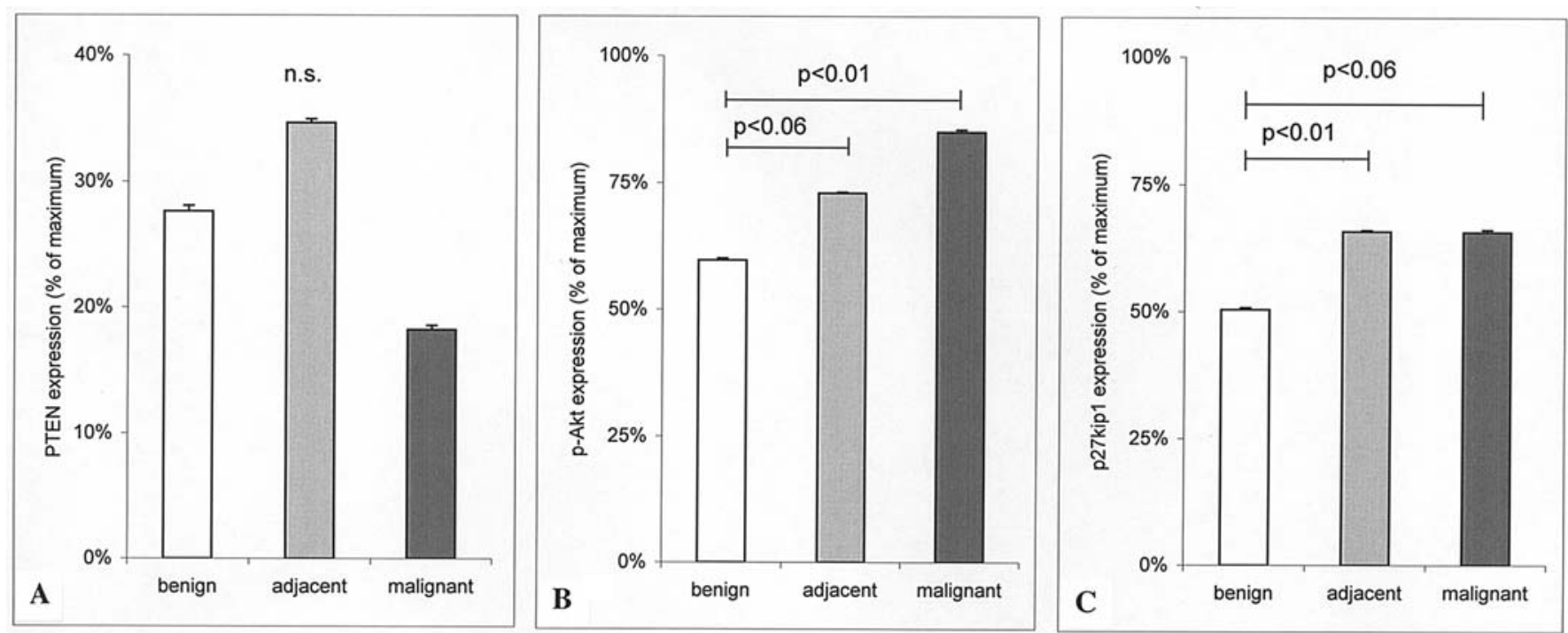

Figure 2. (A) Expression data of PTEN in different areas showing no significance in tendency towards decreased expression in malignant tissue and strongest expression in adjacent area. (B) Expression data of p-Akt in different areas showing significant increased expression in adjacent and malignant tissue and no statistical difference from adjacent area to malignant. (C) Expression data of p $27^{\mathrm{kip} 1}$ in different areas showing significant increased expression in adjacent and malignant tissue and no statistical difference from adjacent area to malignant.

p-Akt, 1:150. After $12 \mathrm{~h}$ of incubation (PTEN, $2 \mathrm{~h}$ ) the sections were washed in TBS and incubated with a secondary biotinylated antibody (Vectastatin Elite ABC Kit, Vector Laboratories, Inc., Burlingame, CA, USA) for $60 \mathrm{~min}$. The DAB system (Vector) was used for visualization according to the manufacturer's instructions. Sections were briefly rinsed in tap water, counterstained with Mayer's Hematoxylin solution and then mounted. For negative control, the primary antibody was replaced by non-immune serum.

All TMA staining was assessed by two independent investigators (A.S.M. and J.H.) in a blind study so that neither of them knew the origin of each TMA. The staining reaction was classified according to a semi-quantitative IHC reference scale ranging from 0-3+ as previously described (19).

Statistical analysis. Staining intensity was analyzed as relative expression levels, in percent, with a maximal staining score of 3 . Since the relative values in percent nested into the respective group of malignant adjacent or benign tissue, samples showed signs of non-normality as determined by the Shapiro-Wilk W-test. The data were analyzed following the arcus sinus square root transformation prior to One-way ANOVA and all-pair Tukey HSD as post hoc analysis. BoxCox-Transformation indicated arcus sinus square root transformation as an appropriate normalization procedure. Paired t-test analysis was performed to compare the individual biomarker expression in tissue samples that had been obtained from the different areas. JMP (SAS Inc.) software was used for all statistical analyses. For graphical representation, data were retransformed and the geometrical mean with its $95 \%$ confidence intervals was plotted.

\section{Results}

Representative staining results are shown in Fig. 1. A median PTEN protein expression of $28 \%$ was detected in benign tissue whereas, in malignant areas, only $18 \%$ expression was found and the adjacent zone showed 35\% expression. PTEN was not significantly altered between the groups with different localization. In tendency, however, PTEN was decreased in the malignant regions and revealed highest staining in the adjacent zone (Fig. 2A).

Both p-Akt and p27kip1 showed a significant increase in staining intensity for malignant tissue (85 and 66\%) when compared to the respective benign tissue $(\mathrm{p}<0.01$ and $\mathrm{p}<0.05$, paired t-test). Interestingly, the adjacent but histopathologically benign tissue had significantly increased levels of p-Akt and p2 $7^{\mathrm{kip} 1}$ with 73 and $66 \%$, if compared to the corresponding benign tissue, which showed a 60 and $50 \%$ intensity level $(\mathrm{p}<0.05$ and $\mathrm{p}<0.01)$. Remarkably, no significant difference was found between the evaluated benign adjacent zone when compared to the malignant tissue analyzed for $\mathrm{p}$-Akt and p27 ${ }^{\mathrm{kip} 1}$ expression (Fig. 2B and C).

Correlation analysis between the three different tissue entities revealed that $\mathrm{p}$-Akt and $\mathrm{p} 27^{\mathrm{kip} 1}$ expression demonstrated a highly significant positive correlation in benign tissue $(\mathrm{p}<0.001)$. In both adjacent $(\mathrm{p}=0.0539)$ and malignant tissue $(\mathrm{p}=0.117)$, no correlation was marked.

\section{Discussion}

This is the first study to demonstrate localized diversity of Akt signalling parameters in prostate carcinoma. Little data is available on p-Akt expression in prostate cancer. Recently, Thomas et al (9) showed proof of Akt activation in prostate cancer tissue. When different tumor grades were compared, activation of Akt in prostate cancer was reported predominantly in advanced cancer of Gleason score 8-10 (20). By including benign prostate tissue in examination, our data demonstrates significant activation of Akt in localized prostate cancer. Paweletz et al (21) showed increased expression of p-Akt at the invasion front. Additionally, our study showed that 
activated p-Akt in prostate cancer tissue was already detectable in adjacent benign areas.

Our data demonstrated altered p27 ${ }^{\mathrm{kip} 1}$ expression in areas outside the histological tumor in histologically benign tissue areas. Several studies report a significant correlation of decreased $\mathrm{p} 27^{\mathrm{kip} 1}$ expression with prostate cancer progression $(14,22,23)$ predominantly in advanced cancer in terms of a late event. However, Graff et al (4) documented increased expression of $\mathrm{p} 27^{\mathrm{kip} 1}$ in the early stage of localized prostate cancer concordant to our observations of increased expression in cancerous tissue.

Correlation of p-Akt and p2 $7^{\mathrm{kip} 1}$ in benign tissue, explained as a controlled regulation of the above mentioned signal cascades, was already lost in the adjacent but histologically benign zone and, to a higher degree, in the malignant tissue cores. Loss of correlation shows uncoupled behaviour of those two parameters according to a loss of controlled regulation in terms of malignancy.

It was shown here that, in relation to molecular parameters p-Akt and p27 ${ }^{\mathrm{kip} 1}$, the adjacent benign tissue areas act like cancerous tissue. In their molecular behaviour, these areas are part of the tumor mass, extending the histologically malign region.

Graff (4) and McMenamin et al (6) characterized decreased expression of PTEN as a chronologically late event in prostate cancer progression. Lower expression levels than in benign prostatic tissue were already detected in localized prostate cancer. Interestingly, this supports the hypotheses of late PTEN loss, but not to a statistically significant extent. Therefore, in localized prostate cancer, no evidence is shown for Akt activation due to decreased PTEN; this may be due to a functional loss. The behaviour of PTEN in the adjacent tissue may be seen as an activation of this known tumor suppressor gene.

The data supports the hypothesis that there might be an inconsistency in the diagnosis of histologically benign prostate tissue. Here, we demonstrated the molecular cancerous behaviour of histologically benign areas; molecular tools might additionally augment diagnosis and prognostication. This might affect the use of partial prostate biopsies, which characterise only small, one-dimensional insights into the condition of the prostate. Further information about the regional diversity of molecular parameters within the prostate is needed to cope with the cancerous prostate's heterogeneity.

\section{Acknowledgements}

This study is supported by a grant from the Federal Ministry of Education and Research (Fö. 01KS9602) and the Interdisciplinary Center of Clinical Research Tuebingen (IZKF). A.S.M. is partially supported by a postgraduate grant from the Novartis Foundation. P.S. is supported by the Fortune program (grant F 1481010).

\section{References}

1. Gleason DF: Histologic grading of prostate cancer: a perspective. Hum Pathol 23: 273-279, 1992.

2. Mostofi FK, Davis CJ Jr and Sesterhenn IA: Pathology of carcinoma of the prostate. Cancer 70 (Suppl. 1): 235-253, 1992.
3. Mostofi FK, Sesterhenn IA and Davis CJ Jr: A pathologist's view of prostatic carcinoma. Cancer 71 (Suppl. 3): 906-932, 1993.

4. Graff JR: Emerging targets in the AKT pathway for treatment of androgen-independent prostatic adenocarcinoma. Expert Opin Ther Targets 6: 103-113, 2002.

5. Hermans KG, van Alewijk DC, Veltman JA, van Weerden W, van Kessel AG and Trapman J: Loss of a small region around the PTEN locus is a major chromosome 10 alteration in prostate cancer xenografts and cell lines. Genes Chromosomes Cancer 39: 171-184, 2004.

6. McMenamin ME, Soung P, Perera S, Kaplan I, Loda M and Sellers WR: Loss of PTEN expression in paraffin-embedded primary prostate cancer correlates with high Gleason score and advanced stage. Cancer Res 59: 4291-4296, 1999.

7. Vazquez F and Sellers WR: The PTEN tumor suppressor protein: an antagonist of phosphoinositide 3-kinase signaling. Biochim Biophys Acta 1470: M21-M35, 2000.

8. Vazquez F, Ramaswamy S, Nakamura N and Sellers WR: Phosphorylation of the PTEN tail regulates protein stability and function. Mol Cell Biol 20: 5010-5018, 2000.

9. Thomas GV, Horvath S, Smith BL, Crosby K, Lebel LA, Schrage M, Said J, De Kernion J, Reiter RE and Sawyers CL: Antibody-based profiling of the phosphoinositide 3-kinase pathway in clinical prostate cancer. Clin Cancer Res 10: 8351-8356, 2004

10. Ramaswamy S, Nakamura N, Vazquez F, Batt DB, Perera S, Roberts TM and Sellers WR: Regulation of G1 progression by the PTEN tumor suppressor protein is linked to inhibition of the phosphatidylinositol 3-kinase/Akt pathway. Proc Natl Acad Sci USA 96: 2110-2115, 1999.

11. Wu X, Senechal K, Neshat MS, Whang YE and Sawyers CL: The PTEN/MMAC1 tumor suppressor phosphatase functions as a negative regulator of the phosphoinositide 3-kinase/ Akt pathway. Proc Natl Acad Sci USA 95: 15587-15591, 1998 .

12. Dreher T, Zentgraf H, Abel U, Kappeler A, Michel MS, Bleyl U and Grobholz R: Reduction of PTEN and p27kip1 expression correlates with tumor grade in prostate cancer. Analysis in radical prostatectomy specimens and needle biopsies. Virchows Arch 444: 509-517, 2004

13. Murillo H, Huang H, Schmidt LJ, Smith DI and Tindall DJ: Role of PI3K signaling in survival and progression of LNCaP prostate cancer cells to the androgen refractory state. Endocrinology 142: 4795-4805, 2001.

14. Tsihlias J, Kapusta LR, De Boer G, Morava-Protzner I, Zbieranowski I, Bhattacharya N, Catzavelos GC, Klotz LH and Slingerland JM: Loss of cyclin-dependent kinase inhibitor p27Kip 1 is a novel prognostic factor in localized human prostate adenocarcinoma. Cancer Res 58: 542-548, 1998.

15. Graff JR, Konicek BW, McNulty AM, Wang Z, Houck K, Allen S, Paul JD, Hbaiu A, Goode RG, Sandusky GE, Vessella RL and Neubauer BL: Increased AKT activity contributes to prostate cancer progression by dramatically accelerating prostate tumor growth and diminishing p27Kip1 expression. J Biol Chem 275: 24500-24505, 2000.

16. Kuefer R, Hofer MD, Gschwend JE and Rubin MA: Tissue microarrays. High-throughput procedures to verify potential biomarkers. Urologe A 43: 659-667, 2004.

17. Kononen J, Bubendorf L, Kallioniemi A, Barlund M, Schraml P, Leighton S, Torhorst J, Mihatsch MJ, Sauter G and Kallioniemi OP: Tissue microarrays for high-throughput molecular profiling of tumor specimens. Nat Med 4: 844-847, 1998.

18. Merseburger AS, Kuczyk MA, Serth J, Bokemeyer C, Young DY, Sun L, Connelly RR, McLeod DG, Mostofi FK, Srivastava SK, Stenzl A, Moul JW and Sesterhenn IA: Limitations of tissue microarrays in the evaluation of focal alterations of bcl-2 and p53 in whole mount derived prostate tissues. Oncol Rep 10: 223-228, 2003.

19. Theodorescu D, Broder SR, Boyd JC, Mills SE and Frierson HF Jr: Cathepsin D and chromogranin A as predictors of long term disease specific survival after radical prostatectomy for localized carcinoma of the prostate. Cancer 80: 2109-2119, 1997.

20. Malik SN, Brattain M, Ghosh PM, Troyer DA, Prihoda T, Bedolla R and Kreisberg JI: Immunohistochemical demonstration of phospho-Akt in high Gleason grade prostate cancer. Clin Cancer Res 8: 1168-1171, 2002. 
21. Paweletz CP, Charboneau L, Bichsel VE, Simone NL, Chen T, Gillespie JW, Emmert-Buck MR, Roth MJ, Petricoin IE and Liotta LA: Reverse phase protein microarrays which capture disease progression show activation of pro-survival pathways at the cancer invasion front. Oncogene 20: 1981-1989, 2001.

22. Kuczyk M, Machtens S, Hradil K, Schubach J, Christian W, Knuchel R, Hartmann J, Bokemeyer C, Jonas U and Serth J: Predictive value of decreased p27Kip1 protein expression for the recurrence-free and long-term survival of prostate cancer patients. Br J Cancer 81: 1052-1058, 2001.

23. Halvorsen OJ, Haukaas SA and Akslen LA: Combined loss of PTEN and p27 expression is associated with tumor cell proliferation by Ki-67 and increased risk of recurrent disease in localized prostate cancer. Clin Cancer Res 9: 1474-1479, 2003. 